\title{
Recent status of hydrotherapy and balneotherapy with clinical beneficial effects
}

\begin{abstract}
In the Complementary and alternative medicine (CAM) and Integrated Medicine (IM), hydrotherapy and balneotherapy have been important treatment. They have several pleiotropic effects, such as thermal effects, buoyancy, hydrostatic pressure, viscous resistance and chemical effects. There is clinical efficacy to various diseases or states, including neck pain, low back pain, knee osteoarthritis, Parkinson disease, and so on. New trial with health promotion strategy with balneotherapy has been reported along World Federation of Hydrotherapy and Climatotherapy.
\end{abstract}

Keywords: hydrotherapy, balneotherapy, Integrated Medicine Japan (IMJ), Complementary and alternative medicine (CAM), Integrated Medicine (IM), active and healthy aging (AHA)
Volume 12 Issue 6 - 2019

\author{
Akiyo Yoshioka,' Hiroshi Bando, 1,2 Yu \\ Nishikiori,' Akinori Nakanishi' \\ 'Shikoku Division of Integrative Medicine Japan (IMJ), Japan \\ ${ }^{2}$ Tokushima University / Medical Research, Tokushima, Japan
}

Correspondence: Hiroshi Bando, Shikoku Division of Integrative Medicine Japan (IMJ), Nakashowa I-6I,Tokushima 770-0943, Japan, Tel +8I-90-3 I87-2485; Fax +8I-88-603-1030; Email pianomed@bronze.ocn.ne.jp

Received: November 07, 2019 | Published: November 14 2019
Abbreviations: CAM, complementary and alternative medicine; IM, integrated medicine; IMJ, integrated medicine Japan; AHA, active and healthy aging; LBP, low back pain; KOA, knee osteoarthritis

\section{Opinion}

Complementary and alternative medicine (CAM) and Integrated Medicine (IM) have been recently understood and prevalent across the world. In Japan, Integrated Medicine Japan (IMJ) has continued various activities until now, in which authors and colleagues have broadened IM activities and assemblies as Shikoku Island division of IMJ for years. Among them, we reported the significance of music therapy ${ }^{1}$ and hydrotherapy/balneotherapy, ${ }^{2,3}$ and others so far. In this article, current topics of balnerotherapy would be introduced and discussed.

In the CAM and IM, there is a group of biological therapy. ${ }^{4} \mathrm{~A}$ variety of treatments in this category have been developed since ancient times. They have been associated with some socio-cultural background, in which hydrotherapy has been continued in several places.

CAM and IM have the category of the use of water, which is hydrotherapy or balneotherapy ${ }^{5}$. They include spas and wellness in our modern social lives, ${ }^{6}$ and show several effects for patients with osteoarthritis, multiple sclerosis and other diseases. ${ }^{7,8}$

The effects of balneotherapy can be related to non-specific factors such as heat. ${ }^{9}$ It can induce the heat shock response, associated with the synthesis and release of heat shock proteins. It can be observed in specific biochemical components such as hydrogen sulfide (H2S) in sulfurous water and radon in radioactive water. Results from several investigations suggest the beneficial effects of balneotherapy and hydrotherapy for immune system and stress response. ${ }^{9}$

There are several pleiotropic effects of the balneotherapy. ${ }^{10}$ They include directs effects such as i) thermal effects (vasodilation, blood pressure reduction, immune activation, metabolism promotion, muscle/fiber softening), ii) buoyancy (reduced weight load, standing and walking training in water), iii) hydrostatic pressure (improvement of pretibial edema, respiratory rehabilitation), iv) viscous resistance (resistance exercise, muscle training in all directions), v) chemical effects with dissolved component (mineral, CO2, H2S, etc.). Furthermore, beneficial influences are expected including psychological effect, spa resort environment effects, ${ }^{10}$ From basic point of view, hydrotherapy has usually three categories, such as thermal, mechanical, and chemical effects. ${ }^{11}$ Thermal effects can utilize heat (35-40 Centigrade, C), body temperature (32-34 C), or cold (8-10 C) therapy. Heat therapy is explained by vasodilation and blood flow facilitation effects, while cold therapy is by vasoconstriction and pain reduction. In particular, heat and cold stimuli can give the effectiveness in reducing musculoskeletal symptoms and promoting post-traumatic recovery. ${ }^{12,13}$ From clinical point of view, hydrotherapy has been one of the rehabilitation treatments for various diseases, including nervous system diseases with a positive result. ${ }^{14}$ It can reduce pain and improve QOL. The action mechanism would be omnidirectional, where there is a positive effect on segmental spinal mechanisms, muscle relaxation, autonomic nervous system. It is usually performed in a warm, shallow pool and may be involved in various exercises such as aerobic, stretching/range of motion, resistance and stability training. ${ }^{15}$ Hydrostatic efficacy in water may alleviate pain by reducing edema and also sympathetic nervous activity. ${ }^{16}$

As to clinical effect of balneotherapy, several portion of the body can be applied and reported from the neck to the knee in the following. There was a systematic review concerning neck pain and the balneotherapy from 13 studies with 658 cases. ${ }^{17}$ The key words included spa treatment, thalassotherapy, hydrotherapy, aquatic therapy or aquatic treatment. There was some evidence that balneotherapy improves QOL better in 4 studies, fair in 8 ad weak in 1 . The therapy for neck pain by different waters and methods have reduced pain and disability, and also improved function capacity, mobility of joints, balance, QOL, relaxation and mood ${ }^{17}$.

Effect of hydrotherapy and peloidotherapy on chronic low back pain (LBP) was studied in 139 subjects. ${ }^{18}$ It included retrospective observational study such as health assessment questionnaire (HAQ), resulting reduction of the pain.

Concerning the effect of spa therapy for chronic low back pain (CLBP), there was a systematic review and meta-analysis. ${ }^{19}$ From 327 studies initially retrieved from databases, 12 RCT studies met the eligibility criteria and were included. The meta-analysis has confirmed that spa therapy can give pain relieving and improve lumbar spine function in patients with CLBP. 
There was a report of the effect of balneotherapy for knee osteoarthritis (KOA) in patients with more than 65 years. ${ }^{20}$ Two groups were compared between balneotherapy only and balneotherapy and physical therapy (PT). The responder rate was $89.0 \%$ vs $98.7 \%$, respectively. Furthermore, the latter contributed to reduced pain, functionality, QOL, fatigue and sleepiness. ${ }^{20}$

For patients with KOA, the effect of balneotherapy and spa therapy was studied as to Quality of Life (QoL). ${ }^{21}$ It was a systematic review and meta-analysis and performed by 17 studies. As a result, there was a long-term pain improvement $\mathrm{ES}=-0.38(95 \% \mathrm{CI}-0.74$ to -0.02$)$, comparing balneological interventions with sham interventions. Consequently, balneotherapy and spa therapy can significantly improve QOL, and may reduce drug consumption as other beneficial effects. ${ }^{21}$

Regarding the Parkinson disease (PD), Systematic review and meta-analysis was performed in 19 studies with 484 cases. ${ }^{22}$ The purpose was to investigate the effect of hydrotherapy for balance, functional mobility, QOL and motor status. As a result, hydrotherapy may improve balance and functional mobility of PD, whether it is combined or not with other therapies. For patients with ankylosing spondylitis, effects of water therapy were studied in the light of disease activity, functional capacity, spinal mobility and pain severity. ${ }^{23}$ It included 8 studies with 383 cases, and showed efficacy by a systematic review and meta-analysis.

Successful innovative integrated care models for chronic diseases has been the targets of the European Innovation Partnership on Active and Healthy Ageing (EIP on AHA). In relation to this activity, an 18day course with balneotherapy and education was performed for many people. ${ }^{24}$ This health promotion strategy for AHA follows the concept of World Federation of Hydrotherapy and Climatotherapy. From health and economic points of view, spa therapy seems to be classified into 12 kinds. ${ }^{25}$ There are resort/hotel spa, casino spa, medical spa (cosmetic, wellness), and so on. These properties can attract many people who want to enjoy various excitement and spa as they like. ${ }^{25}$

\section{Conclusion}

In summary, current trends of hydrotherapy or balneotherapy have been introduced in this article. This description would be expected to become some references for further development of healthier lives worldwide.

\section{Acknowledgments}

None.

\section{Conflicts of interest}

The authors declare that there is no conflicts of interest.

\section{Funding}

None.

\section{References}

1. Bando H, Yoshioka A, Nishikiori Y. Music Therapy in the Hospital to Heal Patients for Training of Speech and Swallow Function. Int $J$ Case Rep Clin Image. 2019;1(2):107.

2. Nakanishi A, Bando H. Development of Health Resort Casino System in Integrative Medicine. Int J Conf Proc. 2019;1(5): ICP.000521.2019.
3. Bando H. Visiting the centers of warm bath therapy in 3 middle Eastern countries. J Compl Altern Med. 2009;6:39-43.

4. Cáceres A. Integrative medicine: a health paradigm of the future. Int $J$ Phytocos Nat Ingred. 2019;6:6.

5. Kavasi N, Csordas A, Nagy K, et al. Occupational exposure assessment at a therapeutic radon spa facility in Hungary. Radiation Protection Dosimetry. 2019;184(3-4):470-473.

6. Vladeva E, Bacheva D, Todorov I. Spas and wellness - A new philosophy for harmony in life. Scrip Sci Sal Pub. 2016;2(2):50-54.

7. Matsumoto H, Hagino H, Hayashi K, et al. (2017) The effect of balneotherapy on pain relief, stiffness, an physical function in patients with osteoarthritis of the knee: a meta-analysis. Clin Rheumatol. 36(8):1839-1847.

8. Corvillo I, Varela E, Armijo F, et al. Efficacy of aquatic therapy for multiple sclerosis: a systemic review. Eur J Phys Rehabil Med. 2017;53(6):944-952.

9. Gálvez I, Torres-Piles S, Ortega-Rincón E. Balneotherapy, Immune System, and Stress Response: A Hormetic Strategy? Int J Mol Sci. 2018;19(6): 1687.

10. Shimodozono M. History of Balneotherapy and Physical Therapy at Kirishima Rehabilitation Center of Kagoshima University Hospital. $J$ Balneol Climatol Phys Med. 2019;82(1):17.

11. An J, Lee I, Yi Y (2019) The Thermal Effects of Water Immersion on Health Outcomes: An Integrative Review. Int $J$ Environ Res Public Health. 2019;16(7):1280.

12. Malanga G, Yan N, Stark J. Mechanisms and efficacy of heat and cold therapies for musculoskeletal injury. Postgrad Med. 2014;127(1):57-65.

13. Garra G, Singer AJ, Leno R, et al. Heat or cold packs for neck and back stain: A randomized controlled trial of efficacy. Acad Emerg Med. 2010;17(5):484-489.

14. Joanna I. Hydrotherapy in nervous system diseases. Journal of Education, Health and Sport. 2019;9(1):55-60.

15. Plecash AR, Leavitt BR. Aquatherapy for neurodegenerative disorders. $J$ Huntingtons Dis. 2014;3(1):5-11.

16. Kamioka H, Tsutani K, Okuizumi $\mathrm{H}$, et al. Effectiveness of aquatic exercise and balneotherapy: a summary of systematic reviews based on randomized controlled trials of water immersion therapies. $J$ Epidemiol. 2010;20(1):2-12.

17. Corvillo I, Armijo F, Álvarez-Badillo A, et al. Efficacy of aquatic therapy for neck pain: a systematic review. Int J Biometeorol. 2019: 10.1007/ s00484-019-01738-6.

18. Yücesoy H, Geçmen İ, Adıgüzel T, et al. Efficacy of balneological outpatient treatment (hydrotherapy and peloidotherapy) for the management of chronic low back pain: a retrospective study. Int $J$ Biometeorol. 2019;63(3):351-357.

19. Bai R, Li C, Xiao Y, et al. Effectiveness of spa therapy for patients with chronic low back pain: An updated systematic review and meta-analysis. Medicine (Baltimore). 2019;98(37):e17092.

20. Dilekçi E, Özkuk K, Kaki B. Effect of balneotherapy on pain and fatigue in elderly with knee osteoarthritis receiving physical therapy: a randomized trial. Int J Biometeorol. 2019;63(12):1555-1568.

21. Antonelli M, Donelli D, Fioravanti A. Effects of balneotherapy and spa therapy on quality of life of patients with knee osteoarthritis: a systematic review and meta-analysis. Rheumatol Int. 2018;38(10):1807-1824.

22. Pinto C, Salazar AP, Marchese RR, et al. Is hydrotherapy effective to improve balance, functional mobility, motor status, and quality of life 
in subjects with Parkinson's disease? A systematic review and metaanalysis. PMR. 2018. pii: S1934-1482(18)30931-6.

23. Liang Z, Fu C, Zhang Q, et al. Effects of water therapy on disease activity, functional capacity, spinal mobility and severity of pain in patients with ankylosing spondylitis: a systematic review and meta-analysis. Disabil Rehabil. 2019:1-8.
24. Blain H, Bernard PL, Canovas G, et al. Combining balneotherapy and health promotion to promote active and healthy ageing: the BalarucMACVIA-LR ${ }^{\circledR}$ approach. Aging Clin Exp Res. 2016;28(6):1061-1065.

25. Tang ILF, Grace CSH, Tan-Chew T, et al. Understanding Generation Y's Favorite Spa Scent, Spa Food Versus Spa Service Experience. J Tourism Hospit. 2018;7:374. 